\title{
Advanced Pedagogical Approaches at Slovak Universities
}

\author{
Pavol Molnár and Ildikó Némethová \\ University of Economics in Bratislava, \\ Slovak Republic
}

\section{Introduction}

This chapter aims to provide a specific insight into the latest forms of modern teaching implemented at designated universities in the Slovak Republic. The main concern is to highlight the greatest benefits of modern educational approaches and then to present their pragmatic and practical applications in tertiary education. Furthermore, this chapter focuses on the provision of reliable data based upon authentic results generated through research projects which are closely linked both to e-learning and complementary web-based teaching practices. The overall scope of this chapter revolves around the following subjects: (1) latest achievements in advanced tertiary educational approaches at Slovak universities; (2) dissemination of gained results in the Leonardo da Vinci Project REDILEM; (3) practical utilisation of e-learning outcomes based upon applied research; (4) benefits of feedback provision in e-learning education; (5) knowledge management as a tool of assessing students' cognitive understanding and holistic comprehension; (6) major advantages and key obstacles in e-learning education; (7) complementary advanced teaching practices.

\section{Advanced pedagogical approaches in tertiary education}

Advanced pedagogical approaches in tertiary education represent innovative efforts in the realm of human activities in the 21st century. Various approaches such as interactive online learning, web-based courses, hyperlinks to websites on the Internet, collaborative learning, online discussion forums, "guided didactic conversations," or "tutorials in print," and blended learning have become significant constituents of innovative learning and teaching techniques and methods.

A plethora of pedagogical activities both in their classical and contemporary forms have been provided by many Slovak higher educational institutions. One of the reasons, except for a unique support of information and communication technology and Internet media, is goodwill (for the universities) and demand (from learners) for this more convenient form of teaching and learning model.

At the outset, it is necessary to stress that in accordance with all these modern pedagogical and didactical approaches the winners are the learners. It has been noticed that such an innovative process of education receives less interest from the teachers, although various lengthy articles, papers and/or books dedicated to this particular matter emphasise the 
importance of web-based education, e-learning and blended learning pedagogical activities. Some of the former and recent results in connection with tertiary (university) education at Slovak universities will be presented throughout this chapter.

A research project KEGA (3/3078/05) entitled "Web-Based Training for Business English and German" has been implemented at the University of Economics in Bratislava, Slovakia. The project has been designed to foster work-related language skills. This particular course has been designed as a blended form of study. It has benefited from the combination of faceto-face classroom learning and an instructor driven presentation and social interaction, which is delivered, online. Throughout the elaboration of this web-based teaching material the authors have accommodated different learning styles (visual, aural, verbal, and social), made the course accessible to learners with special needs, provided a variety of opportunities to accurately assess progress, applied a blend of learning theories (the cognitive learning theory, which promotes learners to control their own learning; and the constructivist learning theory, which challenges learners with tasks that refer to skills and knowledge just beyond their current level of mastery), and so they have set the course apart from the norm.

They have clearly defined the learning objectives, identified the skill gaps of the potential learners, selected the right content, built in a good instructional design including assessment and utilised subject matter experts when creating content. They have also established a support for an effective blended programme, communicated the importance and urgency of the learning programme to their learners, instructed them how to learn online, ensured learners' success by providing them with appropriate technical support, and tried to keep all the learners motivated by facilitating and supporting the entire programme.

As a courseware package and learning management system, they have chosen Moodle that enables the instructor to create powerful, flexible and engaging learning experiences. All the resource materials involve texts, which are intended to convey specific details, and facts that learners can marshal in support of an argument, they are also used for vocabulary enhancement and are supported by JavaScript.

In order to increase the interactivity within Moodle, they have applied the Hotpotatoes Suite. It has allowed teachers to use various evaluation tools to check the quality and accuracy of the acquired knowledge and skills.

Moodle has been suitable for the creation of adequate patterns for the rehearsal of failed answers. When a learner is unable to complete a language problem correctly, it is demonstrated repeatedly until he/she can manage to resolve the problem without mistakes. This technique functions to keep learners revisiting problem areas until their performance improves. Rehearsal is then delivered more widely over time until problems no longer require practice. Rehearsal is more broadly applied for learning new business-related vocabulary. The course uses online newspapers as large collections of authentic texts, which can contribute to rendering learning a foreign language more effective since students will be faced with real language. Throughout the rehearsal task the main emphasis has been to assist learners in getting started in building up a technical English vocabulary. The authors have used the lexical approach which argues that language consists of meaningful chunks that, when combined, produce a continuous coherent text. Activities used to develop learners' knowledge of lexical chains include intensive and extensive online reading in the target language, repetition and recycling of online activities, noticing and practicing 
language patterns and collocations, working with dictionaries and other e-reference tools. Furthermore, they have taken advantage of the eclectic approach based on language performance, as they believe that most learning is preparation for actual performance. Particular negative observations, based on generally acknowledged experience, have been connected with instructors' (teachers') involvements. Both during synchronous and/or asynchronous learning there have been numerous complaints concerning the enormous burden of establishing the necessary contacts between learners and teachers (instructors). In most cases, learners did not have access to the Internet during the week, therefore they could devote their attention to the required resource materials only at the weekends or they were constantly forced to visit some public facilities, e.g. an Internet Café.

The second experience results from the implementations of the Leonardo da Vinci Project, REDILEM, involving nine partners from six European countries (Austria, the Czech Republic, France, Germany, the Slovak Republic, and Sweden) to create a new type of education for SME managers, managed and organised both by representatives of the Slovak Technical University in Bratislava and the University of Economics in Bratislava. The purpose of the project was to combine the theoretical interdisciplinary education with practical training within a learning network. It was intended to support managers of newly established SMEs.

The starting motivation of the project was the intention that products and experiences from the project gained should help various groups of inhabitants to ensure their continual education, and life-long reception of proper knowledge and skills, the improvement of skills and competence, the improvement of quality and the strengthening of relations between professional education and innovations, as well as the creation of new work-places and the improvement of conditions for employment and to improve entrepreneurial abilities and increase competitiveness, especially in regions with high rates of unemployment and restricted possibilities of learning, by the creation of a system of interdisciplinary distance learning for current and prospective managers of Small and Medium-sized Enterprises.

One of the particular aims was to provide learners with interdisciplinary education, since their present education was considered to be excessively one-sided (their orientation was overly technological), in order to increase their flexibility and adaptability to the changing labour market needs, to raise their competitiveness as well as their abilities to co-operate with domestic and foreign partners, mainly their customers and other SME managers. Another important goal was to support the socio-economical development in regions with high rate of unemployment and with a limited access to learning opportunities.

Syllabi, curricula and teaching materials have been designed as a new type of educational material, which requires a form and content of modern e-based learning materials providing an effective and low cost opportunity to gain target-oriented information and knowledge. Therefore, specific study materials have been produced. Reference materials for these courses need specific texts and materials, where reasoning is inevitable; some experts refer to them as "guided didactic conversations" or "tutorials in print." The teacher shall guide learners through the course material via the study guide, ask questions, give instructions and explanations, and communicate in a "language", which learners can easily understand. The design of such teaching materials should resemble the atmosphere and situation characteristic for traditional classroom learning and teaching. 
In order to ensure the quality of the teaching process a manual in the field of "Pedagogy and Methodology" was accomplished. University professors and teachers were trained how to use "multimedia applications" within the framework of the teachers training. The aim of the teacher-training course was to support the teaching staff in course design, particularly in specific methodology and pedagogy, e.g. in distance communication, dialogues, tasks, and other learning activities. On the other hand, the course was designed to support the teachers of web-based learning in developing their paper-based study guides in compliance with the study materials. Furthermore, these study materials were accessible on specific websites and allowed learners to access more detailed information packages. These hyperlinks were selected and provided for learners by experts in the related fields.

Two types of online courses have been applied, namely synchronous and asynchronous. The synchronous online course (analogical with the team discussion) connected professors and learners within the system and they interacted as a classical (face-to-face) discussion group. Learners could "raise their hands" (electronically), and professors answered their questions, etc. Situations were made similar to face-to-face classroom applications.

The asynchronous online course enabled learners to familiarise themselves with particular topics containing aims, glossaries, explanatory notes, case studies, tests, assignments and exercises, questions for discussion, and further reference materials. The verification of their knowledge was accomplished via tests and case studies, as participants uploaded their solutions into the e-learning system. Each case study ended with a set of questions for discussion. The participants could discuss possible solutions with other colleagues using the discussion forum.

Learners were fully responsible for establishing mutual contact with their peers via particular online systems, but in a shifted time frame. Questions were answered some days later. This kind of learning application seemed to be very popular among learners as they highly appreciated the possibility of having access anytime they wanted. Many of them had limited access to computers, even during their business trips, etc. Professors were forced to control and react to learners on a daily basis in order to serve their needs, which, however, put teachers under pressure and, eventually, was in conflict with their other duties, e.g. research and development activities at their universities, elaboration of textbooks and/or conference papers, study materials, etc.

The next relevant experience is related to activities which greatly focused on the implementation of web-based learning within the educational process at a private Bratislava college in the Slovak Republic. The main aim and motivation was to increase the influence and activity of this private university throughout Slovakia. E-learning was one of the instruments to achieve this goal. Maybe, this was one of the reasons why the stimulation of future players (mainly lecturers) did not meet the right response, and the project was finished after the first trial of its introduction.

Most activities have entailed the elaboration of curricula, study materials, negotiations and supporting resources. Frankly speaking, the "state of the piece of art created" did not satisfy the expectations of the founders of the idea. The end result resembled the experience seen in the above-mentioned two cases - an enormous interest from the learners, but a limited enthusiasm demonstrated by the professors. 
Effective experience is crucially associated with feedback in e-learning education. At the University of Economics in Bratislava, some of the subjects are constantly delivered and supported via e-learning applications. A reliable experience was provided by one of our colleagues.

\section{Explanation of the motivation of the authors}

Feedback plays a crucial role in the provision of incessant inducement and motivation for students. A teacher should not only explain new knowledge but also motivate students to continuous preparations. Some students are satisfied with the number of lectures attended which allow them to pass the exams successfully, others would need more time for being dealt with. Such students highly evaluate the presence of e-based learning materials which to a certain extent provide frequent contact with the teaching materials and help them reach the required levels of attainment.

The implementation of ongoing feedback through classical questionnaires could also be realised by using different test-systems, assignments or other applications. Realistic feedback is possible to be achieved by checking a variety of students' assignments, too. The number and quality of assignments received from students renders answers to many questions, which include solutions that enable teachers to understand how well they execute their work. It should also be pointed out that a continuous control of students' work acts as a prerequisite for achieving better results. Selected findings will be later presented here using Moodle in connection with the implementation of feedback.

A teaching experiment was carried out to detect the impact of Moodle utilisation on feedback frequency increase in education during a semester. Full-time students engaged in the field of Database systems and data warehouses were selected for the realisation of the experiment. They were third year students with sufficient experience in the utilisation of IT, and therefore the application of the given system was not a novelty for them. The total number of students, and other participants in the experiment was two hundred. They were divided into six groups. All the results of students' work were continuously evaluated. The obtained results were later compared with the results of the Automated Information System of the university. The results of the experiment are described below.

The author of the experiment tested the hypothesis which assumed that there had been a direct correlation between the number of solutions and the average number of points scored on the test. Contingency tables were generated based on these results, which reflected the relation between the number of solutions and the average number of points scored, and also the dependence of the overall assessment upon the average number and regularity of the assignments faced.

These results indicate the necessity of introducing various forms of feedback between teachers and students. At universities, feedback should occur mainly in the realisation of various tasks, forums, discussions, project implementations, and the like. It is assumed that these assignments must be continuously evaluated and this form of evaluation can act as a stimulus to students' activities. The LMS Moodle seems to be a very appropriate means for the implementation of the abovementioned.

The e-learning application of knowledge management as a tool of assessing students' performance was accomplished at the University of Technology in Kosice (eastern Slovakia). 
Knowledge assessment has been an inseparable part of current e-learning technologies.

Grading is a process, which should answer students' abilities, knowledge, skills etc. In such a way it could be used as important information in the decision making process of external bodies. However, grading is very often required to be relative. It means it does not answer questions about student's knowledge (abilities, skills etc.) but only answers her/his position in a selected (often later unidentified) group of students.

For external bodies (next level educational institutions, employers) it is important to gain assessment of applicant personal abilities, knowledge, skills. In this case relative grading according to selected groups (class, school) is inappropriate. That is why external bodies very often do not take into account the grades acquired at the educational institutions.

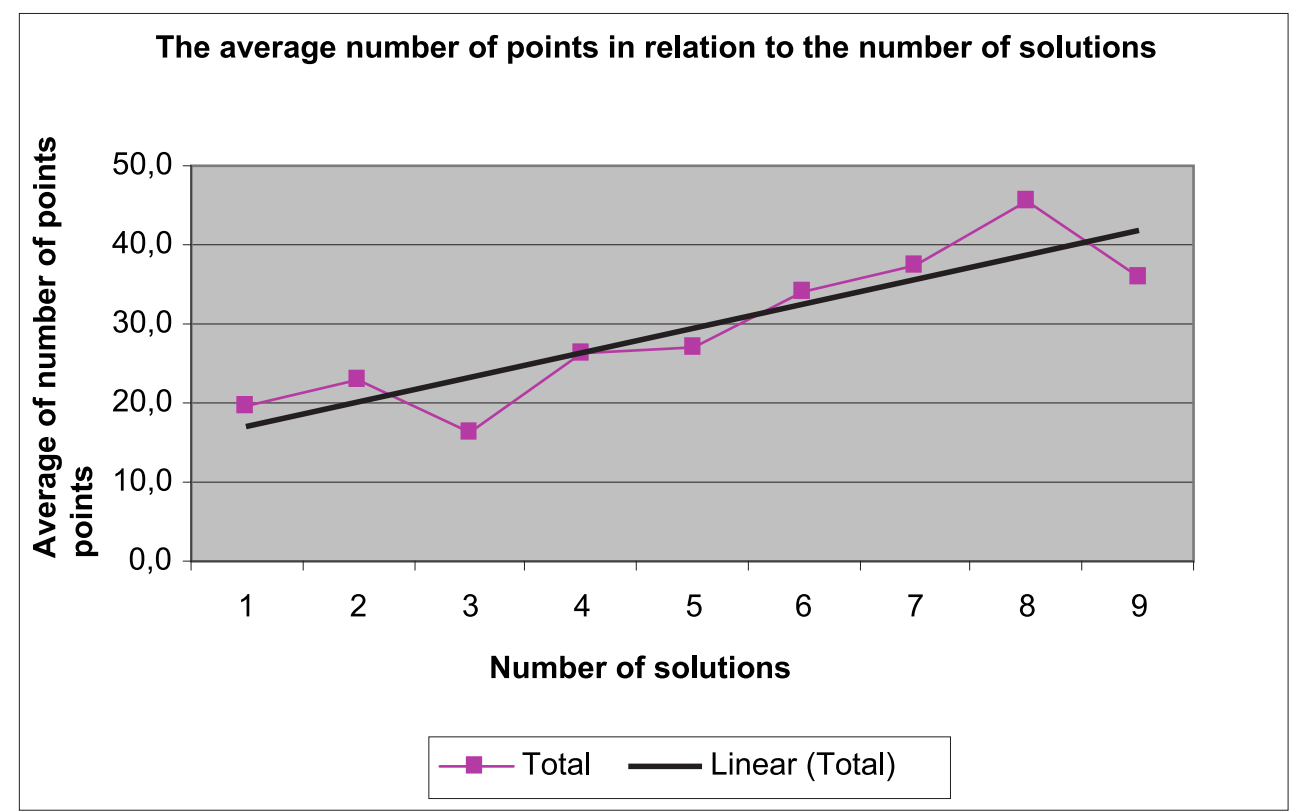

Fig. 1. The relationship between the number of solutions and the average number of points scored during a semester (max. 50). 


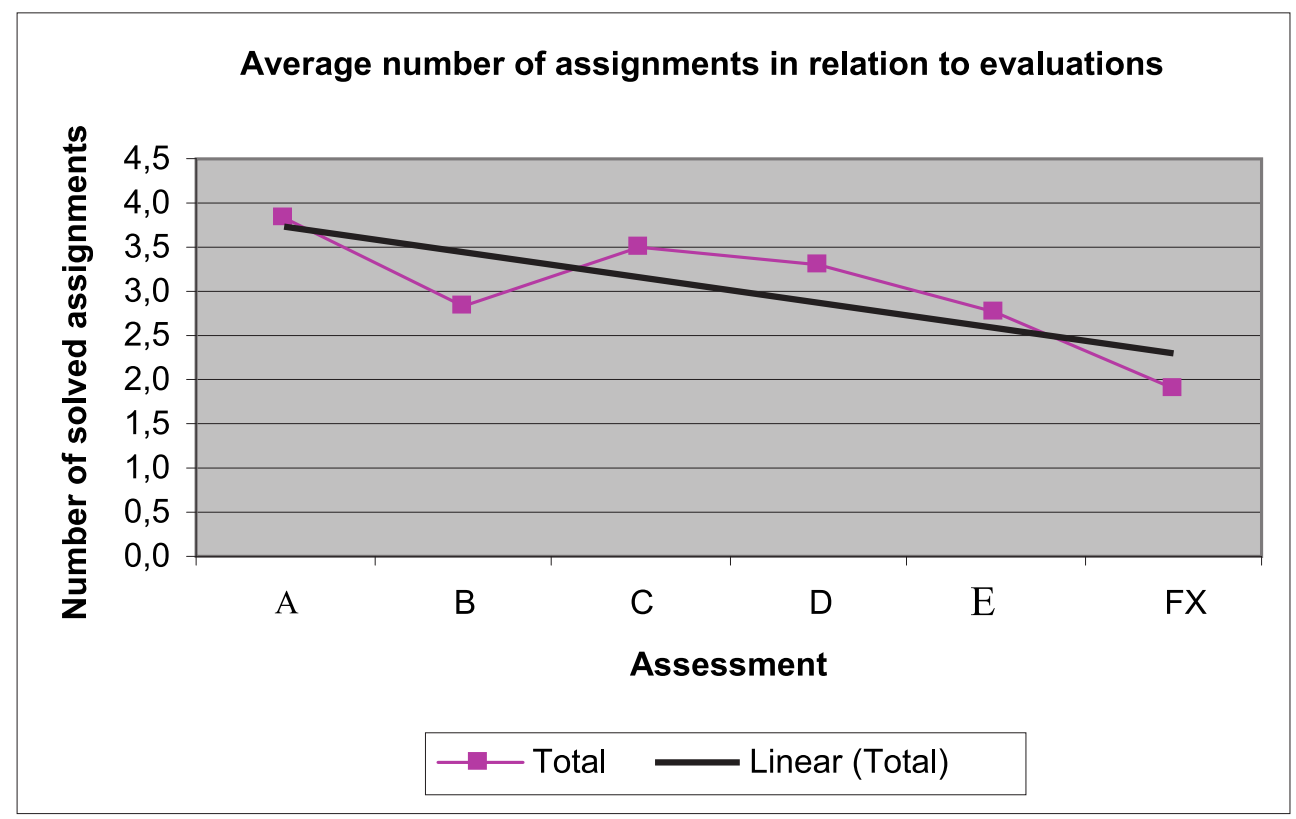

Fig. 2. Dependence of the total assessment of students' tests and the regularity of the assignments faced (the number of solved tasks).

It can be used for students' self-assessment to give them feedback about their progress during their studies or (on the other hand) for intermediate or final grading. However, knowledge tests are not developed with adequate care. Unfortunately, they are not designed to reveal the attained level of knowledge. Moreover, testing suites are very seldom reviewed with regard to their validity and items correlation. Experts at the University of Technology in Kosice examined the LMS Moodle with the aim to develop plug-in modules for the implementation of the ideas described below.

The term "didactic test" is often used in the Slovak and Czech pedagogical communities. It usually denotes the examination process designed for the fair evaluation of the attained level of mastering the given study material. The English speaking communities prefer the term "achievement test."

Regardless of the term preferred, this type of examination is considered as a tool for systematically measuring the teaching outcomes. It has been widely accepted that a didactic/achievement test has to be prepared in accordance to specified rules by a team of specialists.

However, basic principles are not followed in practice during test design and its implementation. Tests are usually developed ad-hoc, without a clear specification of aims, using only basic sets of question items (true-false, one from many choices, sometimes many from many choices). Moreover, testing items are usually not linked with the appropriate 
level of taxonomy of cognitive aims (if any taxonomy is chosen at all) and they are usually developed for specific curriculum sets.

As a result, questions are very often targeted to lower levels of taxonomy (knowledge/ remembering and comprehension/understanding) and in such a way they do not evaluate the participants' knowledge.

The next problem directs attention to the processing of testing results. In every test there is some grading approach specified during test preparation, which is applied to the evaluation of the tested items and, finally, to the evaluation of the entire test. It means that there should be some permanent evaluation of the tested items (finding possible ambiguities, revealing correlations between items, etc.).

There are many causes of the above specified problems. One of them is the inadequate support of knowledge assessment test development methodology in the current learning management systems (LMS). Most systems do not support a wide range of question-item types, these systems have no support of taxonomy of learning objectives and test items are required to be linked to specific chapters, not to appropriate composite knowledge.

Nowadays, assessment test are performed by computer systems. Most computer systems are connected to the Internet without any limitations during testing. Due to increasing computer literacy there is a great chance for participants to "steal" testing items and publish them online in a very short period of time. But even in the case of certain restrictions (fire walled computer classes, restrictions to using computer keyboards for closed type only testing suites), students overcome them by using new technological achievements (i.e. they take a photo of computer screen by mobile phone digital cameras to publish items on-line; use mobile phones for on-line consultancy). In such a way students prove their competence in using technological achievements, but their test results do not reflect their knowledge (skills, abilities).

Learning Management Systems (LMS) have evolved to matured systems in the area of course development during the last ten years. However, it is hard to find any methodology applied to LMS with regard to knowledge assessment. Therefore, the recommended fundamental requirements for knowledge assessment modules of learning management systems with regard to the implementation of assessment methodology are as follows: defining the taxonomy of cognitive aims; defining the cognitive structure of curricula in addition to the basic structure of the curriculum; linking each testing item to an appropriate level of taxonomy and an appropriate mode of cognitive curriculum structure; providing a rich set of question-item types, including open items; supporting item and test life-cycle support; supporting the functionality for teamwork development of tests; providing welldeveloped approaches for items and test statistics".

Application of the so called "functional model" can provide an "added" value for knowledge assessment test development. Linking testing items to specific level of cognitive taxonomy may give possibility to a better selection of the corresponding items. It gives the possibility to test the "knowledge" of participants after lectures and prior to seminars. Newly designed tests can be targeted to checking the comprehension (or higher) level. Moreover, different levels can be combined with the different parts of curriculum. This model seems to be suitable for building an adaptive test. We can start from any level and based upon the correctness or incorrectness of participants' answers we can adjust the level of subsequent items presented to the tested persons. 


\section{Conclusion}

Web-based learning is understood as one of the most important innovations in education. Moreover, this form of learning has many benefits, both social and economic, and belongs to the most flexible types of learning, which suits the target groups of all presented projects learners, current and perspective entrepreneurs, managers and other similar beneficiaries. Moreover, web-based learning is one of the most important possibilities of improving access to continuous vocational training, and lifelong acquisition of the necessary skills and competencies of inhabitants in the regions.

The web-based learning systems, applied in the projects, consist of separate techniques, such as e-learning, self-learning and regular meetings of self-learning groups of learners - three main parts of a blended learning approach.

Teachers' participation in the preparatory phase of these e-learning and blended learning materials and activities was satisfactory and efficient. On the other hand, teachers were less enthusiastic about the day-to-day online contact with their learners. Even very active and zealous colleagues complained about this new approach in tertiary education. Some of them explained that constant participation in online courses, and/or ex-post educational participation represented a significant burden on their mental and physical well-being.

As our present paper suggests, various pros and cons are the real experience outcomes of the presented advanced teaching approaches. The success of any educational change largely depends on how instructors perceive it and what they do to implement change, since it is the instructors who reflect on change, absorb and realise new ideas and improvements.

It goes without saying that these approaches will be realised in a broad extent in the near future. The reasons are as follows: (1) very convenient, rational, effective and time saving ways for learners; (2) support for knowledge-based social environment for regions; (3) engagement in "home working" educational activities in a pleasant ambiance; (4) contribution to the lessening of the burden on the environment in general (e.g. "classroomless" universities, transport-less" commuting/communication, etc.)

This current "pioneer" era requires some inevitable steps to be taken in order to develop and accelerate positive approaches, and to find solutions for diminishing the obstacles within the process. One of the possible ways to eliminate the presence of relevant problems is to involve young teachers in the process, who are much keener on using these innovative means of information and communication technologies.

\section{References}

Brokeš, P. (2005). E-learning - The Most Effective Technique in SME Manager's Distance Education. In.: Proceedings of the Final conference of REDILEM, Bratislava, Slovakia. ISBN 80-89085-37-7

Genči, J. (2007). Some Consideration about Knowledge Assessment. 8th International Conference Virtual University VU'07. E-ACADEMIA SLOVACA, Bratislava, Slovakia. ISBN 978-80-89316-09-0

Kultan, J. (2010) Realizácia spätnej väzby velektronickom vzdelávaní. In.: Proceeding of International Conference on Innovation process in e-learning. University of Economics in Bratislave, Slovakia. ISBN 978-80-225-2724-8 
Molnár, P. (2006). Experience with the Implementation of Leonardo da Vinci Pilot Project REDILEM. In.: Proceeding of International ACEE Conference on Engineering Education. Puerto Rico, USA. ISBN 1-58874-648-8

Molnár, P. (2008). Experiences with Advanced Pedagogical Approaches at Slovak Universities. In: Proceedings of the 9th Biennial ASME Conference on Engineering Systems Design and Analysis, ESDA2008. Haifa, Israel. ISBN 0_7918-3827-7

Némethová, I. (2007). Web-Based Business English. In: Proceeding of International Conference on ProfiLingua. Plzeň, Czech Republic. ISBN 978-80-7043-610-3

Némethová, I. (2009). Controversies in Teaching English for Specific Business Purposes. In: FORLANG 2009: International Conference, Košice. ISBN 978-80-553-0325-3

Sterner, R. (2005). REDILEM and Net-based Learning. In.: Proceedings of the Final Conference of REDILEM, Bratislava, Slovakia. ISBN 80-89085-37-7 


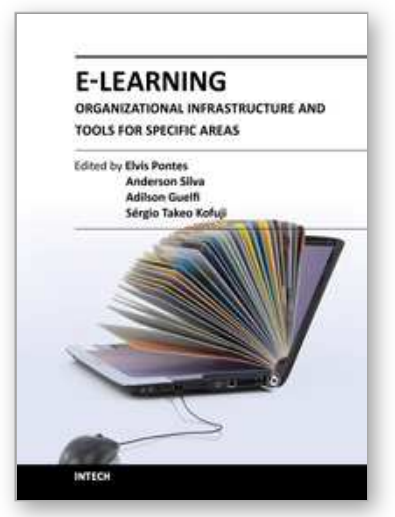

\author{
E-Learning-Organizational Infrastructure and Tools for Specific \\ Areas \\ Edited by Prof. Adilson Guelfi
}

ISBN 978-953-51-0053-9

Hard cover, 182 pages

Publisher InTech

Published online 17, February, 2012

Published in print edition February, 2012

Technology development, mainly for telecommunications and computer systems, was a key factor for the interactivity and, thus, for the expansion of e-learning. This book is divided into two parts, presenting some proposals to deal with e-learning challenges, opening up a way of learning about and discussing new methodologies to increase the interaction level of classes and implementing technical tools for helping students to make better use of e-learning resources. In the first part, the reader may find chapters mentioning the required infrastructure for e-learning models and processes, organizational practices, suggestions, implementation of methods for assessing results, and case studies focused on pedagogical aspects that can be applied generically in different environments. The second part is related to tools that can be adopted by users such as graphical tools for engineering, mobile phone networks, and techniques to build robots, among others. Moreover, part two includes some chapters dedicated specifically to e-learning areas like engineering and architecture.

\title{
How to reference
}

In order to correctly reference this scholarly work, feel free to copy and paste the following:

Pavol Molnár and Ildikó Némethová (2012). Advanced Pedagogical Approaches at Slovak Universities, ELearning-Organizational Infrastructure and Tools for Specific Areas, Prof. Adilson Guelfi (Ed.), ISBN: 978-95351-0053-9, InTech, Available from: http://www.intechopen.com/books/e-learning-organizational-infrastructureand-tools-for-specific-areas/advanced-pedagogical-approaches-at-slovak-universities

\section{INTECH}

open science | open minds

\section{InTech Europe}

University Campus STeP Ri

Slavka Krautzeka 83/A

51000 Rijeka, Croatia

Phone: +385 (51) 770447

Fax: +385 (51) 686166

www.intechopen.com

\section{InTech China}

Unit 405, Office Block, Hotel Equatorial Shanghai

No.65, Yan An Road (West), Shanghai, 200040, China

中国上海市延安西路65号上海国际贵都大饭店办公楼405单元

Phone: $+86-21-62489820$

Fax: $+86-21-62489821$ 
(C) 2012 The Author(s). Licensee IntechOpen. This is an open access article distributed under the terms of the Creative Commons Attribution 3.0 License, which permits unrestricted use, distribution, and reproduction in any medium, provided the original work is properly cited. 